\title{
Factors Associated With Reduced Efficacy of Sitagliptin Therapy: Analysis of 93 Patients With Type 2 Diabetes Treated for 1.5 Years or Longer
}

\author{
Akira Kanamori ${ }^{\mathrm{a}}$, Ikuro Matsuba ${ }^{\mathrm{b}, \mathrm{c}}$
}

\begin{abstract}
Background: Several studies have shown the effectiveness of sitagliptin, a dipeptidyl peptidase- 4 inhibitor, for type 2 diabetes, with a hypoglycemic effect being demonstrated both when it is administered alone or in combination with other oral antidiabetic agents. However, there are few reports about its long-term efficacy, although medications for diabetes need to be effective over the long term. This study (as part of ASSET-K) aimed to investigate the efficacy and safety of sitagliptin when it was administered for 1.5 years or longer, and to explore factors associated with reduction of the therapeutic response.
\end{abstract}

Methods: Out of 375 patients treated with sitagliptin $(50 \mathrm{mg} /$ day $)$ at Kanamori Diabetes Clinic between December 2009 and March 2012, 133 could be followed up for 72 weeks without interruption. After excluding 40 patients in whom the dosage and/or types of concomitant medications were modified during that period, the remaining 93 were included in this analysis. Clinical indices, such as blood glucose, HbA1c, and body weight, were investigated retrospectively. Compliance with diet and exercise therapy at 48 weeks was checked by a questionnaire.

Results: In the 93 patients analyzed (sitagliptin monotherapy, $\mathrm{n}=$ 9; combination therapy, $\mathrm{n}=77$; and switching from an alpha-glucosidase inhibitor or glinide, $n=7)$, hemoglobin A1c (HbA1c) showed a significant decrease after 24 weeks $(7.70 \pm 0.73 \%$ at baseline vs. $6.90 \pm 0.55 \%$ at 24 weeks), but then showed a slight increase at 48 weeks. HbA1c was subsequently maintained in the same range with no significant changes until 72 weeks. A positive correlation was noted between the changes of HbA1c and body weight from 24 to 48 weeks. Compliance with diet and exercise therapy was worse in

Manuscript accepted for publication February 19, 2013

${ }^{a}$ Kanamori Diabetes Clinic, First floor, Prestige Sagami Yume Odori, 8-1-1 Sagamihara, Sagamihara City, Kanagawa 229-0031, Japan

${ }^{\mathrm{b}}$ Matsuba Clinic, 2-159 Tsukagoshi, Saiwai-ku, Kawasaki City,

Kanagawa 212-0024, Japan

${ }^{\mathrm{c} C}$ Corresponding author: Ikuro Matsuba, Matsuba Clinic 2-159

Tsukagoshi, Saiwai-ku, Kawasaki City, Kanagawa 212-0024, Japan.

Email: ikuro@matsuba-web.com

doi: http://dx.doi.org/10.4021/jocmr1256w patients showing $\mathrm{a} \geq 0.3 \%$ increase of $\mathrm{HbA} 1 \mathrm{c}(\mathrm{n}=37)$ from 24 to 48 weeks than in the others $(n=56)$. Multiple logistic regression analysis showed that both factors were independent determinants of the increase of $\mathrm{HbAl}$ c from 24 weeks onward.

Conclusions: Sitagliptin showed good efficacy and safety when administered for 18 months as both monotherapy and combination therapy. Inadequate compliance with diet/exercise therapy and weight again may be associated with an increase of $\mathrm{HbAlc}$ over time during treatment with sitagliptin.

Keywords: Sitagliptin; Type 2 diabetes; Hemoglobin A1c; Longterm administration

\section{Introduction}

Sitagliptin is a dipeptidyl peptidase-4 inhibitor that is used to treat diabetes $[1,2]$, especially patients with type 2 diabetes and reduced incretin activity [3,4]. When administered alone, it has no potential to cause hypoglycemia or weight

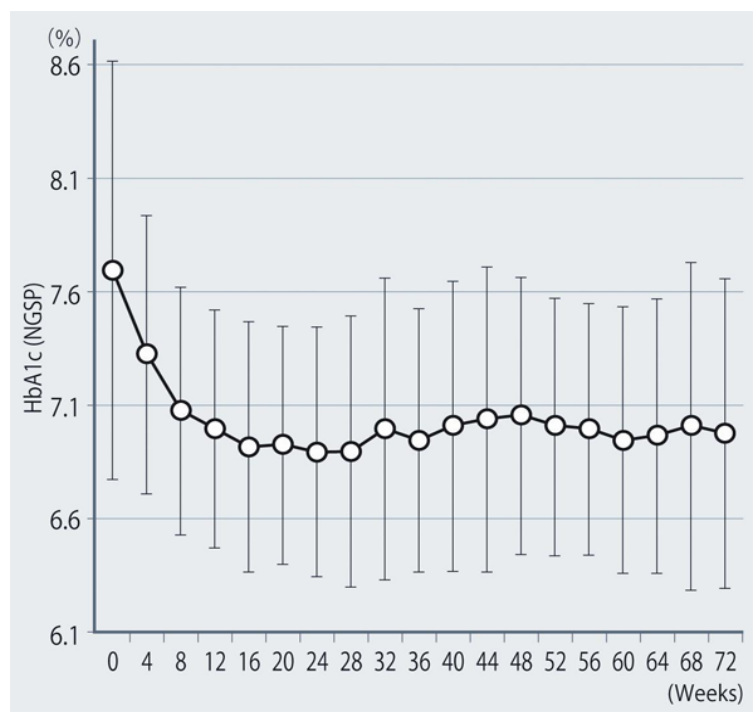

Figure 1. Changes of $\mathrm{HbA} 1 \mathrm{c}(\mathrm{NGSP})$. 


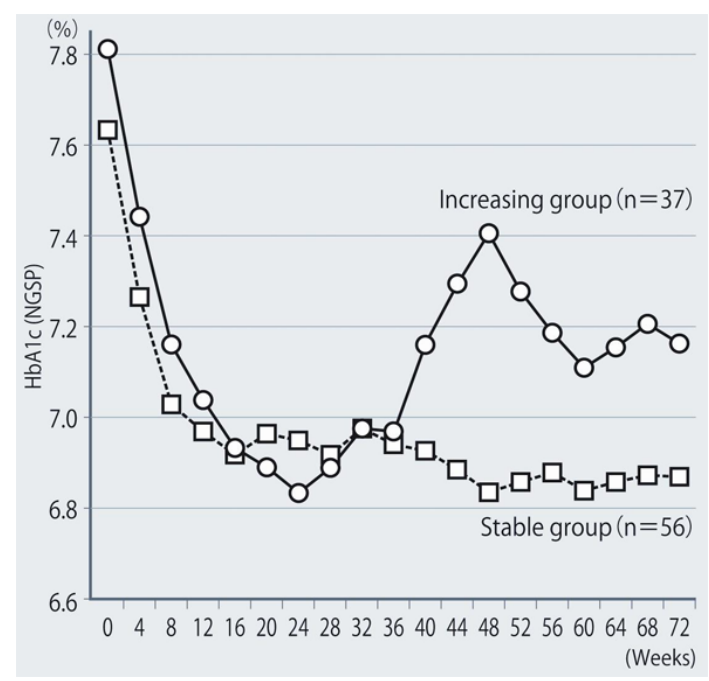

Figure 2. Comparison of groups with stable or increasing HbA1c levels.

gain. More than 2 years have passed since this drug became available clinically in Japan. Several clinical studies on the efficacy of sitagliptin have already been performed [5-10], and have clearly demonstrated that it exhibits a hypoglycemic effect when administered alone or in combination with other oral antidiabetic agents [11-15]. We are currently following 1,332 patients on sitagliptin therapy in the ASSET-K study $[11,12]$. We performed the present analysis because hemoglobin A1c (HbA1c) tended to increase again after 1 year of sitagliptin therapy in the ASSET-K study. The follow-up period was only several months in most of the earlier studies and was a maximum of 1 year even in the clinical studies performed for development of this drug. However, because treatment of type 2 diabetes has to be continued over

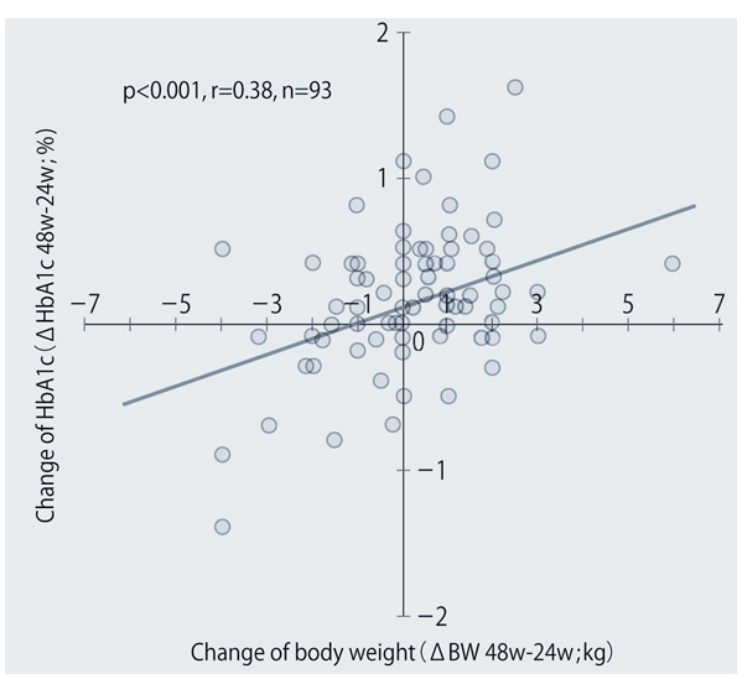

Figure 3. Relationship between the changes of body weight and $\mathrm{HbA} 1 \mathrm{c}$ from 24 to 48 weeks after the start of sitagliptin therapy. very long periods, such as 10 years or more, long-term efficacy and safety have to be confirmed for the drugs used to treat this disease.

Therefore, we conducted a retrospective analysis to investigate the long-term efficacy and safety of sitagliptin. We also aimed to clarify the reason for deterioration of $\mathrm{HbA} 1 \mathrm{c}$ by comparing patients in whom $\mathrm{HbAlc}$ increased with those in whom a stable level was maintained.

\section{Materials and Methods}

\section{Patients}

Of the 375 patients treated with sitagliptin $(50 \mathrm{mg} /$ day $)$ at Kanamori Internal Medicine Clinic between December 2009 and March 2012, 133 could be followed up continuously for 72 weeks. Among them, 40 patients were excluded from the study because the dosage or type of concomitant medications was changed during the follow-up period. Clinical indices, such as blood glucose, $\mathrm{HbAlc}$, and weight, were investigated retrospectively in the 93 patients who could be followed up continuously for 72 weeks without any change in the dosage of sitagliptin or the dosages or types of concomitant medications. Patient compliance with diet/exercise therapy was investigated at 48 weeks by using a questionnaire [16].

\section{Ethical considerations}

The present analysis was conducted as a part of the ASSET$\mathrm{K}$ study. The ASSET-K protocol was devised in accordance with the Declaration of Helsinki and received ethical approval from the institutional review board of the Kanagawa Physicians Association. This study was undertaken in accordance with the Ethical Guidelines for Clinical Studies of the Japanese Ministry of Health, Labor, and Welfare.

\section{Statistical analysis}

Results are given as the mean \pm standard deviation. The profile of changes in each group was compared by the paired $\mathrm{t}$-test, while the t-test and $\chi^{2}$ test were respectively used for comparing continuous variables and categorical variables between the groups. In all analyses, $\mathrm{P}<0.05$ was considered significant.

\section{Results}

The demographic characteristics of the 93 patients were as follows. There were 52 men and 41 women with a mean $( \pm$ SD) age of $63.6 \pm 9.9$ years. The mean duration of disease was $13.9 \pm 6.3$ years, mean body weight was $62.6 \pm 11.9 \mathrm{~kg}$, and mean $\mathrm{HbAlc}$ was $7.70 \pm 0.73 \%$. Sitagliptin was admin- 


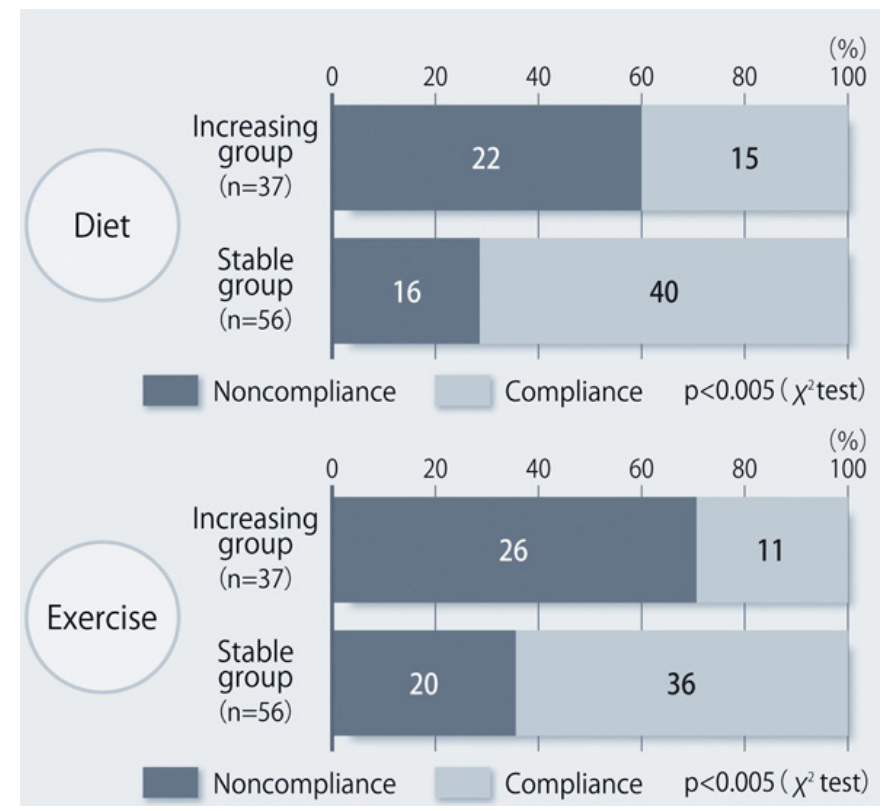

Figure 4. Compliance with diet/exercise therapy at 48 weeks after the start of sitagliptin treatment.

istered as monotherapy to 9 patients, or was combined with 1,2 , and 3 or more other antidiabetic drugs in 30,33 , and 14 patients, respectively. An alpha-glucosidase inhibitor or glinide was replaced by sitagliptin in 7 patients. HbAlc was $7.70 \pm 0.73 \%$ at baseline and showed a significant decrease to $7.33 \pm 0.61 \%$ after 4 weeks, $7.00 \pm 0.52 \%$ after 12 weeks, and $6.90 \pm 0.55 \%$ after 24 weeks of sitagliptin therapy (P $<0.001)$. It subsequently was maintained around that level with no significant change until 72 weeks. There was a slight increase from 24 to 48 weeks, but this was not statistically significant (Fig. 1). The profile of HbAlc up to 72 weeks was similar irrespective of the baseline level and was also similar in the sitagliptin monotherapy and combination therapy groups. Body weight showed no changes from baseline to 72 weeks. At 72 weeks, HbAlc was $<6.9 \%$ in 49 of the 93 patients $(53 \%)$. Achievement of $<6.9 \%$ was more frequent when the baseline $\mathrm{HbAlc}$ was lower. HbAlc decreased gradually with time until 24 weeks, but showed different patterns of change from 24 weeks onward, namely, it did not increase and was stable in some patients, but it increased gradually with time from 24 weeks onward in others (Fig. 2). Clinical features were compared between the group with

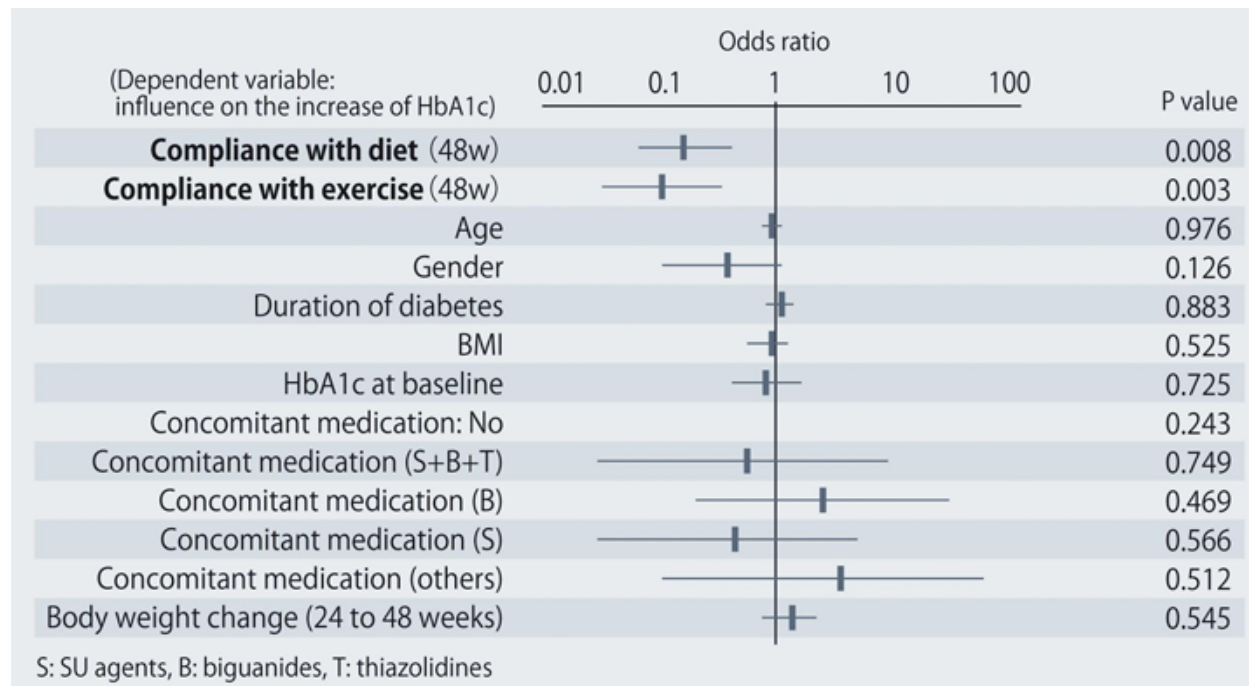

Figure 5. Factors related to $\mathrm{a} \geq 0.3 \%$ increase of $\mathrm{HbA} 1 \mathrm{c}$ from 24 to 48 weeks after starting sitagliptin treatment. 
an increase of $\mathrm{HbA} 1 \mathrm{c}$ by $\geq 0.3 \%$ and the group with an increase of $<0.3 \%$ between 24 and 48 weeks. As a result, none of the clinical indices that we assessed showed a significant difference between the two groups. However, body weight was significantly greater $(\mathrm{P}<0.05)$ at 48 weeks than at 24 weeks in the increasing HbA1c group, while weight showed no significant change in the stable HbA1c group. A weak, but significant, positive correlation $(\mathrm{P}<0.001, \mathrm{r}=0.34)$ was noted between the changes of $\mathrm{HbA} 1 \mathrm{c}$ and body weight from 24 to 48 weeks, suggesting that an increase of HbAlc was associated with an increase of body weight (Fig. 3). At 48 weeks, compliance with diet and exercise therapy was investigated by a survey. As a result, the incidence of noncompliance was significantly higher in the increasing $\mathrm{HbA} 1 \mathrm{c}$ group than in the stable HbAlc group ( $\mathrm{P}<0.005, \chi^{2}$ test) (Fig. 4). Multiple logistic regression analysis was performed to identify factors related to $\mathrm{a} \geq 0.3 \%$ increase of $\mathrm{HbA} 1 \mathrm{c}$ from 24 to 48 weeks. As a result, noncompliance with diet and exercise therapy was found to be significantly related to the increase of $\mathrm{HbAlc}$ during that period (Fig. 5). No serious adverse reactions were noted during this study.

\section{Discussion}

The present report describes the results obtained by followup of Japanese patients with type 2 diabetes for 72 weeks, during which period the dosages of sitagliptin and concomitant drugs for diabetes were not changed. It was confirmed that sitagliptin decreased that $\mathrm{HbA} 1 \mathrm{c}$ level irrespective of the concomitant medications used, being effective for HbAlc, fasting plasma glucose, and postprandial glucose until 24 weeks of treatment. The rate of achieving an $\mathrm{HbAlc}<$ $6.9 \%$ (the target of treatment) was higher when the baseline HbAlc was lower.

It is often noted in clinical practice that $\mathrm{HbA} 1 \mathrm{c}$ increases slightly if sitagliptin is used continuously for 6 months or more and body weight often increases in patients showing an increase of $\mathrm{HbA} 1 \mathrm{c}$. Inadequate compliance with diet and exercise therapy may be the cause of weight gain, but no studies have been done to confirm this. In the present study, we confirmed this for the first time, using data obtained by patient interview. In Japanese patients with type 2 diabetes, $\mathrm{HbA} 1 \mathrm{c}$ has been reported to show seasonal fluctuation, usually decreasing from spring to summer and increasing from autumn to winter [17-20]. Because the patients enrolled in the present study started sitagliptin therapy from December to January, they reached autumn to winter after 44 weeks, when the risk of overeating increases in Japan due to Christmas parties, year-end parties, new year events, and new year parties. Because it is cold, patients probably tend to do less exercise than in summer, resulting in a lack of exercise. Thus, seasonal fluctuation was probably also related to the slight increase of HbAlc during sitagliptin therapy in the present study.

It is known that blood glucose improves until about 1 year after the start of treatment for diabetes, but subsequently increases with time over many years irrespective of the antidiabetic drugs used [21-23]. This phenomenon is described as the so-called secondary ineffectiveness of oral hypoglycemic agents. However, there was no likelihood of the increase of HbA1c in the present study being related to secondary ineffectiveness of sitagliptin [16].

In conclusion, the efficacy and safety of sitagliptin were maintained for 18 months as both monotherapy and combination therapy. In addition, inadequate compliance with diet/exercise regimens and weight gain may be related to the slight increase of $\mathrm{HbAl} \mathrm{c}$ during long-term administration of sitagliptin.

\section{Grant Support}

This study was supported by a grant from the Japan Diabetes Foundation.

\section{References}

1. Lovshin JA, Drucker DJ. Incretin-based therapies for type 2 diabetes mellitus. Nat Rev Endocrinol. 2009;5(5):262-269.

2. Herman GA, Bergman A, Stevens C, Kotey P, Yi B, Zhao P, Dietrich B, et al. Effect of single oral doses of sitagliptin, a dipeptidyl peptidase- 4 inhibitor, on incretin and plasma glucose levels after an oral glucose tolerance test in patients with type 2 diabetes. J Clin Endocrinol Metab. 2006;91(11):4612-4619.

3. Seino Y, Fukushima M, Yabe D. GIP and GLP-1, the two incretin hormones: similarities and differences. J Diabetes Investig. 2010;1(1/2):8-23.

4. Nauck MA, Kleine N, Orskov C, Holst JJ, Willms B, Creutzfeldt W. Normalization of fasting hyperglycaemia by exogenous glucagon-like peptide 1 (7-36 amide) in type 2 (non-insulin-dependent) diabetic patients. Diabetologia. 1993;36(8):741-744.

5. Amori RE, Lau J, Pittas AG. Efficacy and safety of incretin therapy in type 2 diabetes: systematic review and meta-analysis. JAMA. 2007;298(2):194-206.

6. Nonaka K, Kakikawa T, Sato A, Okuyama K, Fujimoto G, Kato N, Suzuki H, et al. Efficacy and safety of sitagliptin monotherapy in Japanese patients with type 2 diabetes. Diabetes Res Clin Pract. 2008;79(2):291-298.

7. Iwamoto $\mathrm{Y}$, Taniguchi $\mathrm{T}$, Nonaka $\mathrm{K}$, Okamoto $\mathrm{T}$, Okuyama K, Arjona Ferreira JC, Amatruda J. Doseranging efficacy of sitagliptin, a dipeptidyl peptidase-4 inhibitor, in Japanese patients with type 2 diabetes mellitus. Endocr J. 2010;57(5):383-394. 
8. Iwamoto Y, Tajima N, Kadowaki T, Nonaka K, Taniguchi T, Nishii M, Arjona Ferreira JC, et al. Efficacy and safety of sitagliptin monotherapy compared with voglibose in Japanese patients with type 2 diabetes: a randomized, double-blind trial. Diabetes Obes Metab. 2010;12(7):613-622.

9. Tajima N, Kadowaki T, Odawara M, Nishi M, Taniguchi T, Arjona Ferreira JC. Addition of sitagliptin to ongoing glimepiride therapy in Japanese patients with type 2 diabetes over 52 weeks leads to improved glycemic control. Diabetol Int. 2011;2:32-44.

10. Odawara M, Kadowaki T, Tajima N, Nishi M, Taniguchi T, Arjona Ferreira JC. Long-term safety, tolerability, and efficacy of the dipeptidyl peptidase-4 inhibitor sitagliptin in Japanese patients with type 2 diabetes. Diabetol Int. 2011;2:94-105

11. Maeda H, Kubota A, Tanaka Y, Terauchi Y, Matsuba I. The safety, efficacy and predictors for $\mathrm{HbA} 1 \mathrm{c}$ reduction of sitagliptin in the treatment of Japanese type 2 diabetes. Diabetes Res Clin Pract. 2012;95(1):e20-22.

12. Kubota A, Maeda H, Kanamori A, Matoba K, Jin Y, Minagawa F, Obana M, et al Efficacy and safety of sitagliptin monotherapy and combination therapy in Japanese type 2 diabetes patients. J Diabetes Investig. DOI: 10.1111/j.2040-1124.2012.00221.x.

13. Kubota A, Matsuba I, Saito T, Nabe K, Seino Y. Secretory units of islets in transplantation index is a useful clinical marker to evaluate the efficacy of sitagliptin in treatment of type 2 diabetes mellitus: J Diabetes Investig. 2011;2(5):377-380..

14. Kubota A, Maeda H, Kanamori A, Matoba K, Jin Y, Minagawa F, Obana M, et al. Pleiotropic effects of sitagliptin in the treatment of type 2 diabetes mellitus patients. J Clin Med Res. 2012;4(5):309-313.

15. Chung HS, Lee MK. Efficacy of sitagliptin when added to ongoing therapy in korean subjects with type 2 diabetes mellitus. Diabetes Metab J. 2011;35(4):411-417.

16. Tajiri Y, Tsuruta M, Ohki T, Kato T, Sasaki Y, Tanaka K, Kono S, et al. Long-term efficacy of sitagliptin for the treatment of type 2 diabetic patients in Japan. Endocr J. 2012;59(3):197-204.

17. Sakura H, Tanaka Y, Iwamoto Y. Seasonal fluctuations of glycated hemoglobin levels in Japanese diabetic patients. Diabetes Res Clin Pract. 2010;88(1):65-70.

18. Sohmiya M, Kanazawa I, Kato Y. Seasonal changes in body composition and blood HbAlc levels without weight change in male patients with type 2 diabetes treated with insulin. Diabetes Care. 2004;27(5):1238-1239.

19. Bouchi R, Babazono T, Mugishima M, Yoshida N, Myumura I, Toya K. Hayashi T, et al. Fluctuations in HbA1c are associated with a higher incidence of cardiovascular disease in Japanese patients with type 2 diabetes. J Diabetes Investig. 2012;3(2):148-155.

20. Matsuhashi T, Sano M, Fukuda K, Kohsaka S, Suzuki Y. Sitagliptin counteracts seasonal fluctuation of glycemic control. World J Diabetes. 2012;3(6):118-122.

21. Kahn SE, Haffner SM, Heise MA, Herman WH, Holman RR, Jones NP, Kravitz BG, et al. Glycemic durability of rosiglitazone, metformin, or glyburide monotherapy. $\mathrm{N}$ Engl J Med. 2006;355(23):2427-2443.

22. Effect of intensive blood-glucose control with metformin on complications in overweight patients with type 2 diabetes (UKPDS 34). UK Prospective Diabetes Study (UKPDS) Group. Lancet. 1998;352(9131):854-865.

23. Satoh J, Takahashi K, Takizawa Y, Ishihara H, Hirai M, Katagiri H, Hinokio Y, et al. Secondary sulfonylurea failure: comparison of period until insulin treatment between diabetic patients treated with gliclazide and glibenclamide. Diabetes Res Clin Pract. 2005;70(3):291297. 